\title{
O conhecimento sobre semântica em manuais de introdução à linguística ${ }^{1}$
}

\author{
Juciane Ferigolo Parcianello² (UFSM)
}

\begin{abstract}
Resumo: Buscamos, neste breve artigo, observar como a Semântica é apresentada, descrita, caracterizada, em dois manuais de iniciação à linguística. O primeiro deles, com publicação datada de 1973, é Introdução à lingüística, de Leonor Scliar Cabral, e o segundo, também intitulado Introdução à lingüística, foi publicado em 2001 e organizado pelas linguistas Fernanda Mussalim e Anna Christina Bentes.
\end{abstract}

Palavras-chave: Linguística; Semântica; Definição.

\section{Considerações iniciais}

(Re)construir a história do (ou de um) conhecimento sobre determinado objeto não é, a priori, relatar uma sequência de fatos, a partir de um recorte temporal, simplesmente tratando estes fatos como dados, como verdades incontestáveis, como resultantes de ações que não poderiam levar a outro fim. Nem traçar um continuum de acontecimentos com base em outros já estabelecidos sem questionar os motivos pelos quais eles aparecem desse modo e não de outro, sem refletir sobre a autoria, sobre os objetivos, sobre a finalidade e sobre o "conteúdo" do relato, do texto.

É pensando dessa forma que nos propomos a realizar um percurso analítico tomando como objeto de análise a categoria Semântica, que figura nos manuais de Linguística. Interessa-nos, como objetivo último, observar o modo como os autores descrevem/definem a Semântica, quais teóricos trazem para tecer as definições, quais subdivisões realizam e por que, onde localizam a Semântica no interior do todo (de todos os ramos: Semântica Formal, Semântica Cognitiva, Semântica Estrutural, Semântica Enunciativa etc.) que constitui a Linguística e, no espaço do sumário, no interior do próprio manual. Dito de outro modo, buscamos responder a seguinte questão: como a Semântica aparece nos livros de iniciação à linguística?

\footnotetext{
${ }^{1}$ Este artigo resulta de um recorte do trabalho final realizado na disciplina História do conbecimento linguístico, ministrada pela Professora Doutora Amanda Eloina Scherer, no Programa de PósGraduação em Letras da Universidade Federal de Santa Maria.

${ }^{2}$ Doutoranda em Letras no Programa de Pós-graduação em Letras da UFSM. Bolsista Capes. Email: jferigolo@yahoo.com.br
} 
Selecionamos dois manuais para a constituição do corpus, levando em consideração a data da primeira publicação, ou seja, tomamos um manual da década de 1970 e outro de publicação recente, já de começos do ano 2000. A realização desse recorte temporal se sustenta no fato de voltarmos nosso olhar para dois momentos bastante distintos da história da semântica: o primeiro, na década de 1970, quando recém começa a ganhar espaço nos manuais de linguística, e, o segundo, nos albores dos anos 2000, quando recebe maior visibilidade, nos manuais, como um ramo da linguística já consolidado.

Acreditamos que este trabalho contribui, mesmo que parcial e modestamente, para a historicização da Semântica no Brasil, já que, para tanto, seguindo a trilha de Auroux (2008, p. 147), é preciso que haja "a constituição e a estrutura dos horizontes de retrospecção, bem como a forma como os domínios de objetos são afetados pela temporalidade".

É nesse sentido que tomamos os manuais Introdução à Lingüística (1974), de Leonor Scliar Cabral, e Introdução à Lingüística (2006), de Fernanda Mussalim e Anna Christina Bentes, não como produções individuais, frutos de um saber sobre a linguagem intrínseco ao pesquisador, mas como resultante das tendências teóricas de uma comunidade científica à qual o estudioso de semântica está vinculado. Ou seja, entendemos que a produção do conhecimento sobre semântica é determinada pelo "air du temps" e pelo "air du lieu" (SÉRIOT, 1999, p. 27) 3 .

\section{A semântica na Introdução à lingüística (1974), de Leonor Scliar Cabral}

Antes de qualquer comentário, elencamos alguns fatos referentes à formação profissional da autora.

O livro Introdução à lingüística, de autoria de Leonor Scliar Cabral, foi publicado em 1973. A autora é Doutora em Linguística pela USP e possui Pós-doutorado pela Universidade de Montréal. Desenvolveu, durante boa parte de sua vida acadêmica, pesquisas em aquisição da linguagem e em psicolinguística. Além do livro acima citado, publicou outros dois: Introdução a psicolingüística (1991) e Abordagem psicolingüística do Sistema alfabético do Português do Brasil (1999), bastante reconhecidos pela comunidade de linguistas do Brasil.

Em Introdução à lingüística (1974) há, inicialmente, uma revisão de alguns conceitos e paradigmas saussurianos, que visam discutir o que é Linguística e quais são suas divisões. Em seguida, encontram-se os vários ramos da Linguística - Fonética, Fonologia, Morfologia, Sintaxe, Lexicologia e

\footnotetext{
3 O "ar do tempo" e o "ar do lugar" são expressões usadas por Patrick Sériot (1999) para referir o conjunto de tendências teóricas e epistemológicas que regem uma determinada comunidade científica, do qual todo o sujeito da ciência participa durante toda a sua vida de pesquisador.
} 
Semântica - e ainda, nos quatro capítulos finais, dedicam-se espaços a 1. Lingua

e Discurso; 2. Variedades lingüisticas; 3. Funcões da linguagem e 4. Expressão e comunicação.

Como apontamos acima, pela referência ao sumário, a Semântica aparece como um ramo da Linguística, localizada entre a (11.) Lexicologia e (13.) Sincronia e diacronia.

No entanto, no capítulo 12, dedicado à Semântica, o tópico Histórico é introduzido da seguinte maneira: "Segundo J. Greimas, a semântica tem sido considerada sempre a parente pobre da lingüística (1974, p. 155)", ou seja, já de início, a Semântica não possui um lugar de prestígio junto ao domínio da Linguística. Na sequência, a justificativa para a afirmação de Greimas advém da problemática do objeto da Semântica:

Uma das causas da dificuldade na delimitação de seu objeto decorre do fato de a semântica se prestar, fundamentalmente, a três tipos de enfoque: o filosófico, o psicológico e o lingüístico. Cada um deles requer especificação de seu objeto e uma metodologia e linguagem exclusivas (SCLIAR CABRAL, 1974, p. 155).

Na sequência, encontramos uma breve descrição de cada um destes enfoques e, ainda, um resumo de algumas teorias semânticas classificadas como pertencentes ao enfoque linguístico.

A Semântica passa a ser considerada um ramo da Linguística, uma vez que "o lingüista pode formalizar um conjunto de regras que, por projeção, revelem os mesmos processos que o falante realiza quando interpreta $\mathrm{o}$ significado das orações" (Ibid., p. 157). Esse seria também o argumento para a Semântica não estar submetida ao domínio filosófico ou psicológico.

Das teorias linguísticas que fundamentam a Semântica, três recebem destaque: 1. Teoria semântica transformacionista; 2. Teoria da Estruturação semântica e 3. Teoria contextual ou situacional.

$\mathrm{Na}$ Teoria semântica transformacionista, são citados os linguistas americanos J. J. Katz e J. A. Fodor e seu artigo The Structure of a Semantic Theory (1963). Para estes pesquisadores transformacionistas, conforme o que consta no texto,

[...] uma teoria semântica deve dar conta da habilidade do falante em determinar $\mathrm{o}(\mathrm{s})$ conteúdo(s) de uma oração, tenha ela uma ou mais interpretações, e, nesse último caso, deve explicar como o falante domina as interpretações possíveis; deve dar conta de como o falante nativo detecta a existência de uma anomalia semântica e é capaz de parafrasear qualquer oração (emprego de sinonímia oracional com estruturas diferentes), em resumo, deve explanar a habilidade do falante nativo para interpretar orações (FODOR; KATZ, 1963 apud SCLIAR CABRAL, 1974, p.158). 
Dito de outro modo, uma teoria semântica transformacionista deve dar conta de explicar como o falante transforma as orações em sentido.

A Teoria da Estruturação semântica é baseada nos estudos de Bernard Pottier, estudioso que realiza uma distinção entre a semântica do discurso (parole) e a semântica da língua. As reflexões desse linguista são fundamentadas na dicotomia estruturalista langue/parole e buscam "explicitar os componentes constantes inerentes a uma categoria", bem como "os efeitos da significação que resulta da união temporal dos elementos no enunciado" (p.158).

E, na teoria contextual ou situacional, reporta-se às pesquisas de Hall e de Halliday, porém, de modo bastante breve, apenas esclarecendo que nos estudos da significação é preciso considerar o contexto de produção dos enunciados, de acordo com a orientação dos linguistas americanos já mencionados.

Observamos que na Introdução à lingüística (1974), de Leonor Scliar Cabral, predominam as correntes semânticas de orientação norteamericana e de base estruturalista/formalista, seguindo a tendência do air $d u$ temps (SÉRIOT, 1999) que a comunidade científica, à qual se vinculava a pesquisadora, seguia. Não há a descrição de outras vertentes da semântica, possivelmente, pela problemática que apresentam em relação à delimitação do objeto, e porque na época - década de 1970 - pouco se conhecia, no Brasil, a respeito dos postulados de E. Benveniste e de O. Ducrot, linguistas que trazem os fundamentos da Semântica Enunciativa ou Semântica PragmáticoEnunciativa.

\section{A Semântica na Introdução à lingüística (2006), de Mussalim e Bentes}

Diferentemente da obra anterior, esta é apenas organizada pelas linguistas Fernanda Mussalim e Anna Christina Bentes. Quem escreve o capítulo dedicado à Semântica é Roberta Pires de Oliveira, Mestre em Semântica e Pragmática pela UNICAMP e Doutora na mesma área, pela Universidade Católica Leuven, na Bélgica.

O livro, publicado pela primeira vez em 2001, é o segundo de uma coleção de três, organizado por Mussalim e Bentes. A Semântica figura nele como um dos oito capítulos que compõem a obra. É o primeiro deles e vem sucedido pela Pragmática, fato que indica uma certa proximidade entre estes dois ramos da Linguística.

O capítulo com o título Semântica é bem mais extenso que o capítulo do livro anteriormente analisado e está divido em cinco sub-capítulos denominados 1. Introdução; 2. A Semântica Formal; 3. A Semântica da Enunciação; 4. A Semântica Cognitiva e 5. Uma rápida conclusão. 
$\mathrm{Na}$ Introdução, afirma-se, de antemão, a dificuldade de se definir o objeto de estudos da Semântica, porque, mesmo havendo consenso entre os semanticistas de que tal objeto é o significado, eles divergem quanto ao modo de compreendê-lo. A essa problemática se soma o fato de que o estudo do significado ultrapassa as fronteiras da Linguística. Esses impasses levam ao desenvolvimento de uma disciplina, que já nasce sob o signo da heterogeneidade; não há, pois, uma Semântica, mas várias Semânticas.

$\mathrm{Na}$ sequência, apresenta-se uma breve descrição de quatro correntes semânticas, sendo tais, a Estrutural, a Formal, a Enunciativa e a Cognitiva. Destas quatro, percebe-se uma ênfase maior em três: na Formal, na Enunciativa e na Cognitiva.

Quanto à Semântica Estrutural, conforme consta no texto, sua rápida menção se deve ao fato de ser pouco praticada, pouco trabalhada, pouco discutida, no atual estágio da Linguística brasileira. As demais semânticas, em contrapartida, seguem sendo a base teórica para um grande número de pesquisas linguísticas.

O outro motivo de tal exclusão seria o fato de que a Semântica Estrutural mantém o paradigma saussuriano significante/significado como fundamento de sua teoria, desconsiderando aspectos que estão fora do sistema linguístico como relevantes para a produção do sentido. Por isso a ênfase na descrição das Semânticas que se afastam, consideravelmente, do Estruturalismo.

Em A Semântica Formal, realiza-se um percurso histórico, partindo de Aristóteles e seu interesse pela significação das palavras e pela relação existente entre elas e o mundo. Como teórico de referência nos estudos da Semântica Formal contemporâneos refere-se Gottlob Frege. Em seguida, explica-se o processo de produção do sentido, com uma série de exemplos. Para essa vertente, o "significado é um termo complexo que se compõe de duas partes, o sentido e a referência" (2006, p. 16).

$\mathrm{N}$ a Semântica da enunciação, o teórico basilar é Oswald Ducrot.

Seguindo o modelo de apresentação das discussões da seção anterior, comenta-se, a partir de uma série de exemplos, como a significação é construída e compreendida nessa corrente semântica: "é o resultado do jogo argumentativo criado na linguagem e por ela" (Ibidem).

A Semântica Cognitiva, por sua vez, tem como marco inaugural, de acordo com o texto, a publicação, em 1980, do trabalho dos linguistas americanos George Lakoff e Mark Johnson. Nesta perspectiva, a significação "é adquirida por meio de nossas manipulações sensório-motoras com o mundo" (2006, p. 19). Após o comentário de vários exemplos, em que o sentido é analisado sob uma perspectiva semântico-cognitiva, finaliza-se o texto do capítulo afirmando a heterogeneidade da Semântica como consequência da complexidade da linguagem. 
Observamos, pois, nesse texto, um destaque maior aos enfoques formalistas da semântica. Já, com relação à Semântica Enunciativa, privilegiamse os trabalhos de Ducrot, os quais se caracterizam, em certa medida, por um viés mais Pragmático. As escolhas da linguista para descrever a(s) Semântica(s), devem-se, provavelmente, a sua formação semântico-pragmática.

\section{Considerações finais}

Com este breve trabalho, percebemos que a Semântica é tomada de modo distinto em um livro de introdução à linguística da década de 1970 e em outro de começos dos anos 2000, isso porque, conforme já mencionamos à luz de Sériot (1999), toda produção de conhecimento se vincula ao air du temps e ao air du lieu, sendo por eles determinada.

A Semântica, em um manual da década de 1970, resume-se à vertente estruturalista e à formalista, pois nesta época o Estruturalismo e Formalismo eram o fundamento dos estudos linguísticos no Brasil.

Já a Semântica apresentada em uma obra do início dos anos 2000 é mais heterogênea, mais multifacetada, menos estrutural. Por ser descrita por uma linguista Doutora em Pragmática, na apresentação da Semântica destacase a contribuição dos estudos pragmáticos a este ramo da linguística.

\section{Referências}

AUROUX, Sylvain. A questão da origem das línguas, seguido de A Historicidade das ciências. Campinas, SP: RG, 2008.

CABRAL, Leonor Scliar. Introdução à lingüística. Porto Alegre, RS: Globo, 1974.

MUSSALIM, Fernanda, BENTES, Anna Christina. Introdução à lingüística. 5. ed. São Paulo: Cortez, 2006.

SÉRIOT, Patrick. Structure et totalité. Paris: Universitaires de France, 1999. 